\title{
Medication adherence and glycemic control in patients with psychotic disorders in the Veterans Affairs healthcare system
}

\author{
Leigh Anne NELSON, Maqual R. GRAHAM, Cameron C. LINDSEY, Rafia S. RASU.
} Received (first version): $14-$ Oct-2010

Accepted: 20-Mar-2011

\begin{abstract}
${ }^{*}$
Objective: To compare antihyperglycemic medication adherence and glycemic control between individuals with schizophrenia and related psychotic disorders and a nonpsychiatric comparison group.

Methods: This was a retrospective medical record review. A total of 124 subjects with diabetes (62 patients with schizophrenia or a related psychotic disorder and 62 randomly selected, age-matched patients without a psychiatric illness) receiving their medical and psychiatric care exclusively through the Kansas City Veterans Affairs healthcare system during 2008 were included in the study. Adherence to antihyperglycemic and antipsychotic medication was determined by refill records obtained through the computerized patient record system to calculate the cumulative mean gap ratio. Hemoglobin A1C values were utilized to compare glycemic control between groups and compared to glycemic goals established by diabetes treatment guidelines. Results: Antihyperglycemic medication adherence was poor for both groups as approximately $60 \%$ of the psychotic disorder group and $75 \%$ of the nonpsychiatric comparison group were without antihyperglycemic medication for greater than 30 days during the 12-month period but adherence did not differ between the groups $(p=0.182)$.

Antipsychotic adherent subjects ( $\geq 80 \%$ adherent) were more likely to be adherent to their antihyperglycemic medication $(p=0.0003)$. There were no significant differences between groups in glycemic control.

Conclusion: Antihyperglycemic medication adherence and glycemic control was less than
\end{abstract}

*Leigh Anne NELSON. Pharm.D., BCPP. Assistant Professor. Department of Research, Kansas City Veterans Affairs Medical Center and Division of Pharmacy Practice and Administration. School of Pharmacy, University of Missouri - Kansas City (United States).

Maqual R. GRAHAM. Pharm.D. Associate Professor Department of Research, Kansas City Veterans Affairs Medical Center and Division of Pharmacy Practice and Administration. School of Pharmacy, University of Missouri - Kansas City (United States).

Cameron C. LINDSEY. Pharm.D. BC-ADM, CDE.

Professor. Department of Research, Kansas City Veterans Affairs Medical Center and Division of Pharmacy Practice and Administration. School of Pharmacy, University of Missouri - Kansas City (United States).

Rafia S. RASU. Ph.D. Associate Professor. Division of Pharmacy Practice and Administration. School of Pharmacy, University of Missouri - Kansas City (United States). optimal for both groups. There were no significant differences in antihyperglycemic medication adherence and glycemic control between patients with a psychotic disorder and those without a psychiatric illness.

Keywords: Medication Adherence. Diabetes Mellitus. Psychotic Disorders. Veterans. United States.

\section{CUMPLIMIENTO DE LA MEDICACIÓN Y CONTROL GLUCÉMICO EN PACIENTES CON DESORDENES PSICÓTICOS EN EL SISTEMA DE SALUD DE LA OFICINA DE VETERANOS}

\section{RESUMEN}

Objetivo: Comparar la adherencia a la medicación antihiperglucémica y el control glucémico entre individuos con esquizofrenia y desordenes psicóticos relacionados y un grupo de comparación no psiquiátrico.

Métodos: Esto fue una revisión retrospectiva de historiales clínicos. Se incluyeron en el estudio a un total de 124 individuos con diabetes (62 pacientes con esquizofrenia o desordenes psicóticos relacionados y 62 pacientes sin enfermedad psiquiátrica aleatoriamente seleccionados y emparejados por edades) que recibían su medicación y sus cuidados psiquiátricos exclusivamente a través del sistema sanitario de la Oficina de Veteranos de Kansas City durante 2008. La adherencia a la medicación antihiperglicemica y antipsicótica se determinó de los registros de recogida de medicación a través del sistema informático para calcular el porcentaje de discordancia medio acumulativo. Se utilizaron los valores de hemoglobina A1C para comparar el control glucémico entre los grupos y comparar con los objetivos glucémicos establecidos en las guias de tratamiento.

Resultados: La adherencia a la medicación antihiperglucémica fue pobre en ambos grupos, ya que aproximadamente el $60 \%$ del grupo de desordenes psicóticos y el $75 \%$ del grupo de comparación no psiquiátrico estuvieron sin medicación antihiperglucémica durante más de 30 días en el periodo de 12 meses pero la adherencia no fue diferente entre los grupos $(p=0,182)$. Los individuos adherentes a los antipsicóticos $(\geq 80 \%$ adherentes) eran más adherentes a sus antihiperglucémicos $(\mathrm{p}=0,0003)$. No hubo 
diferencias significativas entre los dos grupos en el control glucémico.

Conclusión: La adherencia a la medicación antihiperglucémica y el control glucémico fue menos que óptimo en los dos grupos. No hubo diferencias significativas en la adherencia a la medicación antihiperglucémica y al control glucémico entre pacientes con un desorden psicótico y los que no tenían enfermedad psiquiátrica.

Palabras clave: Adherencia a la medicación. Diabetes Mellitus. Desordenes Psicóticos. Veteranos. Estados Unidos.

\section{INTRODUCTION}

Nonadherence to antipsychotic therapy in patients with schizophrenia has been studied extensively as nonadherence can have significant and costly consequences including relapse of psychosis resulting in increased clinic or emergency room visits or hospitalization. ${ }^{1}$ A comprehensive review of the literature reports antipsychotic nonadherence to be $40-50 \%{ }^{2}$ Nonadherence is likely not to be limited to antipsychotic therapy in patients with psychotic illness. Examining medication adherence rates associated with the treatment of comorbid medical illnesses is important as these commonly occur in psychiatric patients, can be drug-induced, and have adverse long-term consequences if not adequately treated. ${ }^{3}$ Mortality in persons with schizophrenia is 2-4 times greater than the general population. ${ }^{4-6}$ Treatment with antipsychotic medications, especially second generation antipsychotics, is linked to increased rates of obesity, diabetes and dyslipidemia. ${ }^{3}$ Although some of the increased risk can be attributed to a higher rate of suicide, lack of appropriate care for chronic medical illnesses, which can include medication nonadherence, may also be a factor associated with increased mortality. Additionally, patients with schizophrenia can have significant cognitive deficits and lack of insight into their disease processes and the need for treatment which can also increase the risk for nonadherence and negative treatment outcomes further justifying the need for studies in this area. ${ }^{7}$

Although adherence to medication regimens for medical disease states such as hypertension, diabetes, and hyperlipidemia has been studied in patients without psychiatric illnesses, few studies have been conducted in patients with comorbid psychiatric illnesses. Adherence to medication regimens for diabetes is less than optimal in patients without psychiatric illnesses ranging from $36-93 \%{ }^{8}$ A published review of the literature from 1975-1996 compared compliance rates with psychiatric medications with those of medication regimens for medical illnesses. ${ }^{9}$ Patients receiving antipsychotics took an average of $58 \%$ (range $24-$ $90 \%$ ) of the recommend quantity of medications as compared to $65 \%$ (range $40-90 \%$ ) in patients receiving an antidepressant and $76 \%$ (range 60 -
$92 \%$ ) in patients with medical illnesses. This study suggests that medication adherence among patients with psychiatric illness may be lower than among patients with medical illnesses. This is an important study as it was the first to compare medication adherence rates between these populations but needs to be interpreted with caution as adherence rates were not assessed by the same measure in all cited studies.

To date, only four studies have specifically evaluated adherence to medication regimens for medical illnesses in a psychiatric patient population and only one of these studies evaluated clinical outcomes. ${ }^{10-13}$ Dolder and colleagues evaluated adherence to nonpsychiatric medications for diabetes $(n=24)$, hypertension $(n=60)$ and hyperlipidemia $(n=28)$ in a sample of middle-aged and older outpatients with schizophrenia or other psychotic disorders receiving care in a Veterans Affairs (VA) healthcare setting. ${ }^{10}$ Medication refill records were used to assess adherence to calculate compliant fill rate (the number of adherent fills in proportion to the total number of prescription fills) and cumulative mean gap ratio (CMGR) (the number of days when medication was unavailable in relation to the total number of days during the same time period). ${ }^{14-16}$ In other words, as the CMGR approaches zero, the more adherent a patient is with prescribed therapy. No significant differences were found between medication classes in terms of compliant fill rate or CMGR at 6 or 12 months $(p=0.086 ; \quad p=0.20$ respectively). Twelve-month compliant fill rates ranged from $52-64 \%$. Twelvemonth CMGR ranged from $5-15 \%$ which means that average gaps in therapy varied from 2-5 days per month. Overall rates of nonadherence were similar for all medication classes. This study concluded that nonadherence rates were suboptimal for both antipsychotic and nonpsychiatric medications in this study population. The retrospective design and small sample size were limitations of this study.

Peitte and colleagues evaluated medication adherence among veterans with schizophrenia and comorbid diabetes and hypertension $(n=1,686){ }^{11}$ Adherence was assessed for each medication type by calculating medication possession ratios (MPR) which measures the total number of days of medication supplied by the number of days needed. This study found only a moderate correlation between adherence to antipsychotic medication and adherence to drug therapy regimens for diabetes and hypertension. In a multivariate analyses adjusted for days' supply of medication dispensed, the adjusted odds for nonadherence were significantly greater for antihyperglycemic (adjusted OR 1.5; $p<0.001$ ) and antihypertensive (adjusted OR $1.5 ; p<0.001)$ medications than antipsychotic medication.

The most recently published study evaluated adherence to antihyperglycemic medication in patients with $(n=11,454)$ and without $(n=10,560)$ schizophrenia receiving care in the VA healthcare system. ${ }^{12}$ Nonadherence was defined as a MPR less than 0.8 reflecting less than $80 \%$ of medication needed for continuous treatment was taken. This 
study found that the prevalence of medication adherence (MPR $=0.8-1.2$ ) to antihyperglycemic medication was significantly higher (51\% vs. $46 \%$; $\mathrm{p}<0.0001)$ and the prevalence of antihyperglycemic medication nonadherence $(\mathrm{MPR}<0.8)$ was significantly lower $(43 \%$ vs. $52 \%$; p $<0.0001)$ in diabetes patients with schizophrenia than without schizophrenia. This study is the largest to date comparing adherence to antihyperglycemic medication among diabetes patients with and without schizophrenia.

Dolder and colleagues compared antihypertensive medication adherence and blood pressure control among middle-aged and older outpatients with schizophrenia or other psychotic disorders $(n=89)$ as compared to age-matched patients without a psychiatric illness $(n=89) .{ }^{13}$ Refill records were used to assess adherence using CMGR and electronic records were used to obtain blood pressure readings. There was no difference in the CMGR ratio between groups $(p=0.71)$ with mean adherence rates reflecting approximately 40 days without antihypertensive treatment during the 1-year study. Despite similar adherence rates, attainment of blood pressure goal was achieved less often in the psychiatric group as compared to the nonpsychiatric group, which could be associated with a poorer outcome. Although the study utilized a retrospective design and had a limited sample size, this is the only study evaluating differences in a clinical outcome for a medical illness between patients with and without a comorbid psychotic illness. This study supports the need for further prospective evaluation of blood pressure control between these patient groups. Furthermore, with the conflicting adherence information coupled with the lack of clinical outcomes for other commonly encountered medical illnesses, such as diabetes and hyperlipidemia, pilot data is needed.

The purpose of our study was to compare antihyperglycemic medication adherence and glycemic control between outpatients with schizophrenia and related psychotic disorders and age-matched individuals without psychiatric illness.

\section{METHODS}

\section{Patient Selection}

The study was approved by the University of Missouri-Kansas City Adult Health Sciences Institutional Review Board and the Kansas City Veterans Affairs Medical Center (KCVAMC) Human Studies and Research and Development Committees. The Veterans Health Administration is the United States largest integrated health care system. Approximately 150 medical centers and community-based outpatient clinics provide primary and specialty care for more than five million veterans annually. The KCVAMC currently provides services to over 43,000 veteran patients. Hospitalbased services of the KCVAMC include, but are not limited to, acute care medicine, surgical and mental health care. In addition, this medical center offers additional medical and surgical specialty services including geriatric, neurology, cardiology, pulmonary, psychiatry, gastrointestinal and oncology medicine. Subjects were drawn from individuals identified as being prescribed an oral agent for the treatment of diabetes and hyperlipidemia during 2008 using the KCVAMC computer database. From this criteria, we then selected for inclusions those who: 1) had a minimum of two oral antihyperglycemic and antihyperlipidemic prescriptions (i.e. at least 60 days' worth of medication) filled during the 12month study period and; 2 ) were receiving their general medical care including treatment for diabetes and hyperlipidemia exclusively at the KCVAMC Primary Care Clinics providing a sample of 9,606. Patients with Type I Diabetes receiving insulin were not included in the study. Of these subjects, two study groups were formed based on 1) those with a psychotic disorder and 2) those without a diagnosis of psychiatric illness. To identify the psychotic disorder group, subjects receiving a prescription for any oral antipsychotic medication during the same timeframe were identified from the previous sample. Of 248 subjects, we selected for inclusion those who: 1) had a minimum of two oral antipsychotic prescriptions filled (i.e. at least 60 days' worth of medication) during the 12-month study period and; 2) were receiving their psychiatric care exclusively at the KCVAMC. Patients whose primary treatment for psychosis was a long-acting injectable antipsychotic were excluded. The computerized patient record system (CPRS) was utilized to confirm ICD-9 diagnostic codes for diabetes (ICD-9 code 250), hyperlipidemia (ICD-9 code 272) in both groups along with schizophrenia, schizoaffective disorder or psychosis not otherwise specified (ICD-9 codes 295.1, 295.2, 295.3, 295.4, 295.6, 295.7, 295.9, 298.9) for the psychotic group. Additionally, this process was used to verify lack of a psychiatric illness in the nonpsychiatric comparison group.

Sixty-two subjects with a psychotic illness were identified as meeting all inclusion criteria including receiving medications for a psychotic illness, diabetes and hyperlipidemia. All were included in the study. An equal number of age-matched individuals (within 4 years) without a psychiatric illness were randomly selected from the original pool.

Subjects receiving the following classes of antihyperglycemic medications were included in the study: biguanides (metformin), sulfonylureas (glyburide, glipizide), and/or thiazolidinediones (rosiglitazone, pioglitazone). These medication classes are the most commonly prescribed oral agents to treat diabetes at the KCVAMC and metformin is considered first line pharmacotherapy for the treatment of diabetes based on treatment guidelines. ${ }^{17}$ All three antihyperglycemic medication classes were used to identify the original study sample. Subjects receiving HMG-CoA reductase inhibitors, commonly referred to as statins, were included in the study as they are the most commonly prescribed class of antihyperlipidemic medications at the KCVAMC and represent first line pharmacotherapy for hyperlipidemia based on treatment guidelines. ${ }^{18}$ Use of a HMG-CoA 
reductase inhibitor was used to identify the original study sample.

If the subject was receiving combination therapy for the treatment of hyperlipidemia, data were also collected for the following antihyperlipidemic medications: fibrates, niacin, bile acid resins and ezetimibe. Subjects receiving a first generation antipsychotic (FGA) and/or second generation antipsychotic (SGA) in an oral formulation were included in the study. Medications in both classes of antipsychotics were used to identify the original study sample as both classes have utility in the treatment of schizophrenia. ${ }^{19}$

Data was collected from subjects having both diabetes and hyperlipidemia to compare two samples with an additional diabetes disease state management indicator and to reduce a potential confounder of less aggressive care in either group. We will only report outcomes associated with diabetes in this manuscript.

\section{Data Collection}

Electronic medical record review from the CPRS during 2008 was used to collect demographic and clinical information including age, gender, ethnicity, body mass index $(\mathrm{BMI})^{20}$, psychiatric and nonpsychiatric diagnoses ${ }^{21,22}$, duration of illness, smoking status, institutional encounters occurring in 2008 (i.e. primary care clinic visits, nonpsychiatric and psychiatric emergency room visits and hospitalizations), and medication history. All laboratory assessments for hemoglobin A1C (A1C) documented in 2008 were also collected.

Adherence to antihyperglycemic and antipsychotic medication was determined by refill records obtained through the CPRS in 2008. For each subject, rates of adherence were determined for both classes of medication and for each medication within a class if the subject was using combination therapy for the treatment of diabetes and/or psychosis. If a subject was taking more than one medication for diabetes or psychosis, the medication with the greatest nonadherence was selected for the adherence assessment.

Medication adherence was assessed by calculating the CMGR. ${ }^{14-16}$ CMGR is calculated by dividing the number of days of medication that were unavailable for consumption (due to delayed refills) by the total number of days during the same time period. CMGR ratios provide a continuous assessment of gaps in therapy for each subject's antihyperglycemic and antipsychotic medication. This method of assessing adherence has been used in previous studies evaluating antipsychotic and nonpsychiatric medication adherence. ${ }^{10,11,13,23}$

In addition to calculating antihyperglycemic medication adherence rates, A1C values were utilized to compare glycemic control between groups. These values were evaluated in relation to the glycemic goals established by the Standards of Medical Care in Diabetes-2008. ${ }^{17}$ Adequate glycemic control was determined by comparing each subject's $\mathrm{A} 1 \mathrm{C}$ with the treatment goals set by these guidelines. The percentage of A1C measurements that met the target goal was calculated for each subject and the mean percentage of measurements that met goal was then compared between the groups.

\section{Statistical Analysis}

Descriptive statistical analysis for all study variables were defined by mean, standard deviation, and interquartile range (IQR) for continuous variables. Frequency and percentages for categorical variables were reported. Demographic and outcomes variables were assessed for statistical significance between treatment groups using bivariate analysis (e.g. Pearson's chi square test, $F$ test, t-test). Statistical software Stata 9 was used for statistical analysis. A p-value of $<0.05$ was considered significant.

\section{RESULTS}

\section{Patient and Treatment Characteristics}

A comparison of baseline demographic data and clinical characteristics for the psychosis and nonpsychiatric comparison groups is found in Table 1. Overall, both groups were composed mostly of males, who were obese and had hyperlipidemia and at least two additional medical disorders other than diabetes. No significant differences between the age-matched groups were found for BMI, duration of diabetes, medical comorbidities, or healthcare utilization (primary care visits and hospitalizations) for medical needs. There was a significant difference between the groups with regard to race with fewer whites and more blacks composing the psychosis group as compared to the nonpsychiatric group. The percentage of smokers in the psychosis group was higher $(37.1 \%$ vs. $14.5 \%$; $p=0.004)$. Additionally, subjects in the psychosis group had more emergency room visits for a medical reason than the nonpsychiatric comparison group $(p=0.001)$.

The majority of the subjects in the psychosis group were diagnosed with schizophrenia (67.7\%). Most were prescribed a SGA $(n=53 ; 85 \%)$ with risperidone being the most common $(n=17 ; 27.4 \%)$ followed by ziprasidone $(n=10 ; 18.9 \%)$. Other SGA prescribed to subjects included olanzapine, quetiapine and aripiprazole. Eighteen subjects $(29.0 \%)$ were prescribed a FGA with 7 of these subjects $(38.9 \%)$ receiving it in combination with a SGA. With respect to antihyperglycemic medications, individuals were prescribed similar agents. No significant differences existed between groups in the medication classes (biguanides, sulfonylureas, thiazolidinediones) prescribed in terms of the use of monotherapy vs. combination therapy (see Table 1). Additionally, there were no significant differences for the antihyperglycemic agent used in the assessment of adherence for individual subjects (see Table 1). 


\begin{tabular}{|c|c|c|c|}
\hline Parameter & $\begin{array}{c}\text { Subjects without a } \\
\text { psychiatric Illness }(\mathrm{N}=62)\end{array}$ & $\begin{array}{c}\text { Subjects with } \\
\text { psychosis }(\mathrm{N}=62)\end{array}$ & P-value \\
\hline Age (years), mean (SD) & $59.3(2.2)$ & $57.9(7.0)$ & 0.155 \\
\hline $\begin{array}{r}\text { Gender, } N(\%) \\
\text { Male }\end{array}$ & $61(98.4)$ & $60(96.8)$ & 0.559 \\
\hline $\begin{array}{r}\text { Ethnicity, } \mathrm{N}(\%) \\
\text { White } \\
\text { Black } \\
\text { Other }\end{array}$ & $\begin{array}{l}43(69.4) \\
8(12.9) \\
11(17.7)\end{array}$ & $\begin{array}{l}28(45.2) \\
22(35.5) \\
12(19.3)\end{array}$ & 0.008 \\
\hline Body Mass Index $\left(\mathrm{kg} / \mathrm{m}^{2}\right)$, mean $\pm \mathrm{SD}$ & $34.5 \pm 7.4$ & $33.5 \pm 6.3$ & 0.447 \\
\hline $\begin{array}{l}\text { Body Mass Index Classification } 20, \mathrm{~N}(\%) \\
\left.\text { Underweight (BMI }<18.5 \mathrm{~kg} / \mathrm{m}^{2}\right) \\
\text { Normal weight }\left(\mathrm{BMI} 18.5-24.9 \mathrm{~kg} / \mathrm{m}^{2}\right) \\
\left.\text { Overweight (BMI } 25-29.9 \mathrm{~kg} / \mathrm{m}^{2}\right) \\
\left.\text { Obesity Class I (BMI } 30-34.9 \mathrm{~kg} / \mathrm{m}^{2}\right) \\
\left.\text { Obesity Class II (BMI } 35-39.9 \mathrm{~kg} / \mathrm{m}^{2}\right) \\
\left.\text { Obesity Class III (BMI } \geq 40 \mathrm{~kg} / \mathrm{m}^{2}\right)\end{array}$ & $\begin{array}{l}0(0) \\
3(4.8) \\
14(22.6) \\
21(33.8) \\
12(19.4) \\
12(19.4)\end{array}$ & $\begin{array}{l}0(0) \\
3(4.8) \\
18(29.0) \\
18(29.0) \\
14(22.6) \\
9(14.6)\end{array}$ & 0.859 \\
\hline Duration of Diabetes (years), mean (SD) & $5.3(3.1)$ & $6.5(5.4)$ & 0.081 \\
\hline $\begin{array}{l}\text { Psychiatric Disorder, N (\%) } \\
\text { Schizophrenia } \\
\text { Schizoaffective Disorder } \\
\text { Psychosis, Not Otherwise Specified }\end{array}$ & NA & $\begin{array}{l}42(67.7) \\
18(29.1) \\
2(3.2)\end{array}$ & NA \\
\hline $\begin{array}{l}\text { Comorbid Medical Diagnoses, N (\%) } \\
\text { Hyperlipidemia } \\
\text { Hypertension } \\
\text { Coronary Artery Disease (CAD) or Other CAD } \\
\text { Risk Equivalent }{ }^{*} \\
\text { Total Comorbid Medical Diagnoses }{ }^{* *}, \mathrm{~N}(\%) \\
1 \\
2 \\
3 \\
4\end{array}$ & $\begin{array}{l}62(100) \\
50(80.6) \\
18(29.0) \\
6(9.7) \\
25(40.3) \\
24(38.7) \\
7(11.3)\end{array}$ & $\begin{array}{l}62(100) \\
50(80.6) \\
10(16.1) \\
3(4.8) \\
24(38.7) \\
25(40.3) \\
10(16.2)\end{array}$ & $\begin{array}{l}1.000 \\
1.000 \\
0.086 \\
0.666\end{array}$ \\
\hline Smoking, N (\%) & $9(14.5)$ & $23(37.1)$ & 0.004 \\
\hline $\begin{array}{l}\text { Health Care Utilization, mean (SD) } \\
\text { Primary Care Visits } \\
\text { Medical Emergency Room Visits } \\
\text { Psychiatric Emergency Room Visits } \\
\text { Medical Hospitalizations } \\
\text { Psychiatric Hospitalizations } \\
\end{array}$ & $\begin{array}{l}3.1(2.1) \\
0.5(1.0) \\
0 \\
0.08(0.27) \\
0\end{array}$ & $\begin{array}{l}2.6(2.6) \\
1.9(2.8) \\
0.31 \\
0.24(0.64) \\
0.34(1.2)\end{array}$ & $\begin{array}{l}0.209 \\
0.001 \\
0.073\end{array}$ \\
\hline $\begin{array}{l}\text { Antihyperglycemic Medication Classes Prescribed, N (\%) } \\
1 \text { Medication Class/Drug } \\
\geq 2 \text { Medication Class/Drugs }\end{array}$ & $\begin{array}{l}32(51.6) \\
30(48.4)\end{array}$ & $\begin{array}{l}36(58.1) \\
26(41.9)\end{array}$ & 0.470 \\
\hline $\begin{array}{l}\text { Antihyperglycemic } \\
\text { Calculation, N (\%) } \\
\text { Metformin } \\
\text { Sulfonylurea } \\
\text { Thiazolidinedione }\end{array}$ & $\begin{array}{l}39(62.9) \\
21(33.9) \\
2(3.2)\end{array}$ & $\begin{array}{l}34(54.8) \\
23(37.1) \\
5(8.1)\end{array}$ & $0.833^{* * *}$ \\
\hline \multicolumn{4}{|c|}{$\begin{array}{l}\text { *Other Coronary Artery Disease (CAD) Risk Equivalent = Cerebrovascular Disease, Peripheral Artery Disease, Abdominal Aortic } \\
\text { Aneurysm } \\
\text { ** Total Comorbid Diagnoses included the following disease states found in the chronic disease score instrument which uses } \\
\text { pharmacy data to measure an individual's comorbidity (CAD, peripheral artery disease, abdominal aortic aneurysm, smoking } \\
\text { hypertension, asthma, chronic obstructive pulmonary disease, rheumatoid arthritis, cancer, Parkinson's disease, seizure disorder } \\
\text { peptic ulcer disease, glaucoma and migraine headaches) }{ }^{21,22} \text { Hyperlipidemia was also included in the number of total comorbic } \\
\text { diagnoses. }\end{array}$} \\
\hline
\end{tabular}

\begin{tabular}{|l|l|l|l|}
\hline \multicolumn{1}{|c|}{ Table 2. Glycemic Control in Psychosis and Nonpsychiatric Comparison Subjects } \\
\hline \multicolumn{1}{|c|}{ Parameter } & $\begin{array}{c}\text { Subjects without a } \\
\text { psychiatric Illness (N=62) }\end{array}$ & $\begin{array}{c}\text { Subjects with psychosis } \\
\text { (N=62) }\end{array}$ & P-value \\
\hline Hemoglobin A1C - baseline, \% mean (SD) & $6.9(1.7)$ & $7.0(1.4)$ & 0.679 \\
\hline Hemoglobin A1C - final, \% mean (SD) & $7.1(1.6)$ & $7.0(1.6)$ & 0.790 \\
\hline Hemoglobin A1C - change from baseline to endpoint, \% & $0.2(2.0)$ & $0.1(1.2)$ & 0.582 \\
mean (SD) & & & 0.370 \\
\hline Hemoglobin A1C <7\% - final, N (\%) & $42(68.2)$ & $38(61.3)$ & 0.266 \\
\hline Hemoglobin A1C at goal, N (\%) & & $33(53.2)$ & \\
$100 \%$ of assessments & $32(51.6)$ & $2(3.2)$ & \\
$75-99 \%$ of assessments & $3(4.8)$ & $4(6.5)$ & \\
$50-74 \%$ of assessments & $12(19.4)$ & $2(3.2)$ & \\
$25-49 \%$ of assessments & $4(6.5)$ & $4(6.5)$ & \\
$1-24 \%$ of assessments & $0(0)$ & $17(27.4)$ & \\
$0 \%$ of assessments & $11(17.7)$ & \\
\hline
\end{tabular}




\section{Adherence}

Metformin was used to calculate the cumulative mean gap ratio in $58.9 \%$ of the subjects, sulfonylureas in $35.5 \%$ and thiazolidinediones for the remainder. No significant difference in the CMGR for antihyperglycemic medications was found between the psychosis (mean $=15.8 \%$, $\mathrm{SD}=16.8$ ) and nonpsychiatric (mean $=19.7 \%$, $S D=15.6)$ comparison groups $(p=0.182)$. The mean adherence rates reflected approximately 58 days without medication in the psychosis group and 72 days in the nonpsychiatric comparison group during the 12-month period. Figure 1 depicts the months per year antihyperglycemic medication was not consumed based on refill data for both groups. For each subject's antihyperglycemic adherence calculation, the total number of days of therapy assessed during 2008 was tabulated. No difference between the two groups was found for metformin $(p=0.186)$ with a mean duration of assessment for the overall sample of 279 days $(S D=113)$ or sulfonlyureas $(p=0.684)$ with a mean duration of assessment for the overall sample of 278 days $(\mathrm{SD}=125)$.

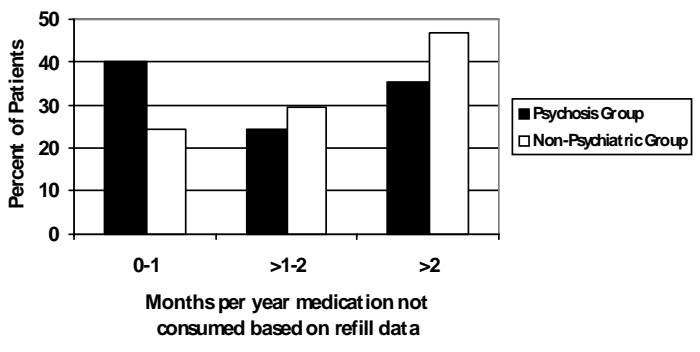

Figure 1. Antihyperglycemic Medication Adherence Psychosis and Nonpsychiatric Comparison Subjects

The antipsychotic CMGR for subjects in the psychosis group was $18.3 \%(S D=16.4)$ indicating approximately 68 days without medication during the 12-month period. Figure 2 depicts the months per year antipsychotic medication was not consumed based on refill data. The mean duration of assessment for the SGA for which the majority of the psychosis group was receiving was 262 days $(S D=104)$. For the psychosis group, there was a significant correlation between antipsychotic and antihyperglycemic medication adherence. If the subject was $\geq 80 \%$ adherent to their antipsychotic therapy, they were more likely to be adherent to their antihyperglycemic therapy $(p=0.0003)$. Antipsychotic adherent subjects had an antihyperglycemic CMGR of $10.7 \% \quad(S D=10.2)$ indicating approximately 39 days without antihyperglycemic medication during a 12-month period. Antipsychotic nonadherent subjects, defined as an adherence rate $<80 \%$, had an antihyperglycemic CMGR of $26.6 \% \quad(\mathrm{SD}=22.3)$ indicating approximately 97 days without drug therapy for their diabetes.

\section{Glycemic Control}

A1C taken in primary care outpatient clinics were evaluated to assess glycemic control by using established diabetes treatment goals. ${ }^{17}$ There were no significant differences between groups in glycemic control (see Table 2). Fifty-three percent of the psychosis subjects were at goal for A1C on all glycemic assessments during 2008 while $51.6 \%$ of the nonpsychiatric comparison group met this outcome. Twenty-seven percent of the subjects in the psychosis group did not obtain an A1C goal of $<7 \%$ at any time during the study period as compared to $17.7 \%$ of the nonpsychiatric comparison group.

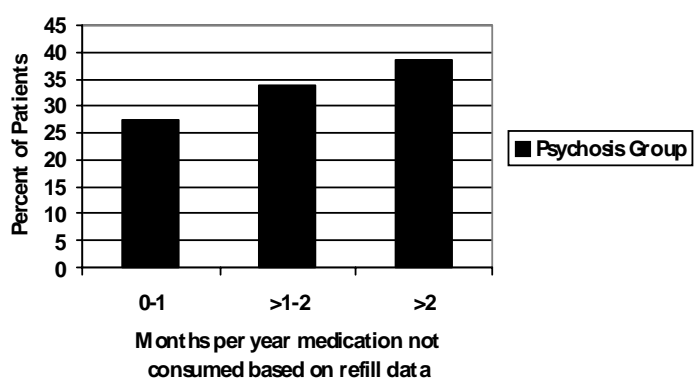

Figure 2. Antipsychotic Medication Adherence in Subjects with Psychosis

\section{DISCUSSION}

Our study is the first to date to compare both glycemic control and medication adherence rates for oral antihyperglycemic agents in patients with psychosis compared to patients without psychiatric illness. Our study found no difference in antihyperglycemic medication adherence between groups. The only other published study comparing antihyperglycemic medication adherence between these two patient populations found that the prevalence of antihyperglycemic medication adherence was significantly greater (MPR=0.8-1.2) and antihyperglycemic medication nonadherence $(\mathrm{MPR}<0.8)$ was significantly lower in diabetes patients with schizophrenia than without schizophrenia. ${ }^{12}$ Our study did find a relationship between adherence rates for antipsychotic and antihyperglycemic medication. If a patient took at least $80 \%$ of the prescribed antipsychotic, they were significantly more likely to be adherent to their drug therapy for diabetes.

We did not find any published studies that specifically compared antihyperglycemic medication adherence rates and clinical outcome (i.e. glycemic control) between patients with psychosis and a nonpsychiatric control group. The study by Dolder and colleagues is the only study of this kind but evaluated blood pressure control. ${ }^{13}$ This study reported differences in blood pressure control between groups with the psychosis group having significantly less blood pressure control than an age-matched nonpsychiatric comparison group although there was no difference in antihypertensive medication adherence between groups. Our study found no significant difference between groups for glycemic control with both baseline and final A1C values being nearly identical between groups.

The finding of no significant differences between groups for antihyperglycemic medication adherence 
and glycemic control is surprising as several studies have found depression to be associated with a higher likelihood of antihyperglycemic medication nonadherence and poor diabetes control. ${ }^{24-26}$ Schizophrenia is one of the most disabling psychiatric illnesses and can be associated with a lack of insight and judgment and, similar to depression, has cognitive deficits associated with the disease. Thus one would expect psychiatric illness in general and, specifically schizophrenia, to negatively impact adherence and clinical outcomes for medical illnesses. Additionally, previous literature has reported disparities in the quality of diabetes care received by patients with a psychiatric illness compared to patients without a psychiatric illness. $^{27}$

Our study supports a growing body of literature that suggests the quality of care for adequate diabetes control is not compromised for those patients with diabetes and psychiatric illness as compared with those without psychiatric illness who are receiving ongoing care. ${ }^{28-33}$ Two of these studies were conducted in the VA healthcare setting which is directly applicable to our study population. ${ }^{28,31}$ Despite our finding that there was no significant difference in antihyperglycemic medication adherence between groups, the overall rate of medication adherence for both groups was less than optimal as approximately $60 \%$ of the psychosis group and $75 \%$ of the nonpsychiatric comparison group were without antihyperglycemic medication for greater than 30 days during the 12-month period. Additionally, approximately $18 \%$ of the psychosis group and $27 \%$ of the nonpsychiatric comparison group did not achieve goal for A1C at any assessment: $19 \%$ and $10 \%$, respectively, had A1C values over $9 \%$. Irregardless of this lack of goal attainment, our study demonstrated fewer patients with poor glycemic control, defined as A1C over $9 \%$ by the National Committee on Quality Assurance, compared with other insured populations in the commercial $(28.4 \%)$, Medicare $(29.4 \%)$ or Medicaid (44.8\%) systems during 2008. ${ }^{34}$

Medication adherence may have been enhanced due to increased healthcare utilization in the psychotic disorder group. These subjects had significantly more visits to the emergency room for medical reasons than the nonpsychiatric comparison group $(p=0.001)$. Additionally, there was also a trend for more medical hospitalizations in the psychotic disorder group $(p=0.073)$. Due to their psychiatric illness, subjects in the psychotic disorder group had additional healthcare interactions. In addition to psychiatric emergency room visits and psychiatric hospitalizations, typically patients with schizophrenia and other related psychotic disorders require outpatient services through Behavioral Health. Therefore, subjects in the psychotic disorder group most likely received care or services offered beyond that given to the subjects without a psychiatric illness. These healthcare system interactions could have provided an opportunity to improve medication adherence.
The findings of our study must be interpreted with consideration to the retrospective design and small sample size, which likely impacted our results. We had strict inclusion criteria which resulted in only 62 subjects for the psychotic group in the specified timeframe. In addition to the small sample size, other study limitations exist. Our study focused specifically on a sample within the VA healthcare system which represented a primarily older, male subset thus our results may not generalize to other segments of the US population. We had strict inclusion criteria with the intent to make the psychosis and nonpsychiatric comparison group comparable on demographic and treatment-related variables which further narrowly defined our study population. The VA healthcare system places a significant amount of emphasis on the quality of processes and outcomes of diabetes care which may differentiate the diabetes care received in this setting from other healthcare settings in the community. Our results may not generalize to patients receiving insulin therapy or long-acting injectable antipsychotics as they were excluded from the study. Direct measurement of medication adherence was not possible due to the retrospective study design. CMGR was used as an indirect measurement of adherence which is calculated based on refill rates. The act of refilling a medication may not accurately reflect medication use and consumption, although this method is objective and has been correlated with other adherence behaviors. ${ }^{35-38}$

Notwithstanding these limitations, our study has several strengths. This was conducted as an evaluation of normal clinical practice. Use of refill records to assess adherence did not interfere with normal processes and allowed for a naturalistic estimation of adherence. We included all patients who met criteria in the psychosis group and did not exclude patients for any reason (i.e. treatment resistance, history of medication nonadherence, comorbid substance abuse/dependence) thus reflecting a typical psychosis population. Other strengths of our study were inclusion of only those patients who received all of their medical and psychiatric care through the VA healthcare system, exclusion of all psychiatric diagnoses in the nonpsychiatric comparison group, and exclusive use of $\mathrm{A} 1 \mathrm{C}$ values obtained in the primary care clinics which limited possible confounders. The use of widely accepted treatment guidelines for diabetes provides validity to the outcome measures selected for this study. Lastly, the 12-month assessment period is also a strength of our study.

\section{CONCLUSIONS}

Our study found no significant differences in antihyperglycemic medication adherence and glycemic control between outpatients with schizophrenia and related psychotic disorders and age-matched individuals without psychiatric illness receiving care in the VA healthcare system. Antihyperglycemic medication adherence and glycemic control was less than optimal for both groups. Adherence with antipsychotic medication 
was found to be significantly associated with antihyperglycemic medication adherence. Additional research in this area should be conducted and include a larger sample size, replication in the VA healthcare system and non-VA sites in the community, and use of multiple measures of adherence.

\section{ACKNOWLEDGEMENTS}

This publication is the result of work supported with resources and the use of facilities at the Veterans Affairs Medical Center, Kansas City, Missouri.
The authors would like to thank Monica Schaefer, Pharm.D., Cynthia Infranca, Harsh Gupta, Harivarun Kalluri, Jennifer Fitzgerald and Parjoel Karki, Doctor of Pharmacy Candidates, for their assistance with this project.

\section{CONFLICT OF INTEREST}

Authors attest that we have no financial or material interest to disclose, and have not received any outside funding or support for this manuscript. .

\section{References}

1. Byerly MJ, Nakonezny PA, Lescouflair E. Antipsychotic medication adherence in schizophrenia. Psychiatric Clinics of North America 2007;30:437-452.

2. Lacro JP, Dunn LB, Dolder CR, Leckband SG, Jeste DV. Prevalence of and risk factors for medication nonadherence in patients with schizophrenia: a comprehensive review of recent literature. J Clin Psychiatry 2002;63:892-909.

3. Consensus development conference on antipsychotic drugs and obesity and diabetes. Diabetes Care 2004;27:596-601.

4. Koranyi EK. Morbidity and rate of undiagnosed physical illnesses in a psychiatric clinical population. Arch Gen Psychiatry 1979;36:414-419.

5. Tsuang MT, Perkins K, Simpson JC. Physical diseases in schizophrenia and affective disorders. J Clin Psychiatry 1983;44:42-46.

6. Allebeck P, Wistedt B. Mortality in schizophrenia. Arch Gen Psychiatry 1986;43:650-653.

7. Keefe RSE. Cognitive deficits in patients with schizophrenia: effects and treatment. J Clin Psychiatry 2007;68:8-13S.

8. Cramer JA. A systematic review of adherence with medications for diabetes. Diabetes Care 2004;27:1218-1224.

9. Cramer JA, Rosenheck R. Compliance with medication regimens for mental and physical disorders. Psychiatric Services 1998;49:196-201.

10. Dolder CR, Lacro JP, Jeste DV. Adherence to antipsychotic and nonpsychiatric medications in middle-aged and older patients with psychotic disorders. Psychosomatic Medicine 2003;65:156-162.

11. Piette JD, Heisler M, Ganoczy D, McCarthy JF, Valenstein M. Differential medication adherence among patients with schizophrenia and comorbid diabetes and hypertension. Psychiatric Services 2007;58:207-212.

12. Kreyenbuhl J, Dixon LB, McCarthy JF, Soliman S, Ignacio RV, Valenstein M. Does adherence to medications for type 2 diabetes differ between individuals with vs without schizophrenia. Schizophrenia Bulletin 2010;36:428-435.

13. Dolder CR, Furtek K, Lacro JP, Jeste DV. Antihypertensive medication adherence and blood pressure control in patients with psychotic disorders compared to persons without psychiatric illness. Psychosomatics 2005;46:135-141.

14. Sikka R, Xia F, Aubert RE. Estimating medication persistency using administrative claims data. Am J Managed Care 2005;11:449-457.

15. Steiner JF, Prchazka AV. The assessment of refill compliance using pharmacy records: methods, validity, and application. J Clin Epidemiology 1997;50:105-116.

16. Hamilton RA, Briceland LL. Use of prescription refill records to assess patient compliance. Am J Hosp Pharm 1992;49:1691-1696.

17. Standards of Medical Care in Diabetes-2008. American Diabetes Association. Diabetes Care 2008;31:S12-S54.

18. Third Report of the Expert Panel on Detection, Evaluation, and Treatment of High Blood Cholesterol in Adults (Adult Treatment Panel III, or ATP III) http://www.nhlbi.nih.gov/guidelines/cholesterol/atp3full.pdf (Accessed September 23, 2008).

19. Texas Medication Algorithm Project (TMAP) A Collaborative Effort. http://www.dshs.state.tx.us/mhprograms/pdf/TIMASCZAlgoAlgorithm.pdf. Accessed June 3, 2010.

20. US Department of Health and Human Services, NIH-NHLBI. Clinical Guidelines on the Identification, Evaluation and Treatment of Overweight and Obesity in Adults. NIH publication no. 00-4084. Bethesda, MD: National Institutes of Health, 2000.

21. Von Korff M, Wagner EH, Saunders K. A chronic disease score from automated pharmacy data. J Clin Epidemiol 1992;45:197-203.

22. Putnam KG, Buist DSM, Fishman P, Andrade SE, Boles M, Chase GA, Goodman MJ, Gurwitz JH, Platt R, Raebel MA, Arnold Chan K. Chronic disease score as a predictor of hospitalization. Epidemiology 2002;13:340-346.

23. Dolder CR, Lacro JP, Dunn LB, Jeste DV. Medication adherence: is there a difference between typical and atypical agents? Am J Psychiatry 2002;159:103-108.

24. Katon W, Russo J, Lin EHB, Heckbert SR, Karter AJ, Williams LH, Ciechanowski P, Ludman E, Von Korff M. Diabetes and poor disease control: Is comorbid depression associated with poor medication adherence or lack of treatment intensification? Psychosomatic Medicine 2009;71:965-972.

25. Lin EH, Katon W, Von Korff M, Rutter C, Simon GE, Oliver M, Ciechanowski P, Ludman EJ, Bush T, Young B. Relationship of depression and diabetes self-care, medication adherence, and preventative care. Diabetes Care 2004;27:2154-2160. 
26. Gonzalez JS, Safren SA, Delahanty LM, Cagliero E, Wexler DJ, Meigs JB, Grant RW. Symptoms of depression prospectively predict poorer self-care in patients with Type 2 diabetes. Diabet Med 2008;25:1102-1107.

27. Frayne SM, Halanych JH, Miller DR, Wang F, Lin H, Pogach L, Sharkansky EJ, Keane TM, Skinner KM, Rosen CS, Berlowitz DR. Disparities in diabetes care: impact of mental illness. Arch Intern Med 2005;165:2631-2638.

28. Desai MM, Rosenheck RA, Druss BG, Perlin JB. Mental disorders and quality of diabetes care in the veterans health administration. Am J Psychiatry 2002;159;1584-1590.

29. Dixon LB, Kreyenbuhl JA, Dickerson FB, Donner TW, Brown CH, Wolheiter K, Postrado L, Goldberg RW, Fang L, Marano C, Messias E. A comparison of type 2 diabetes outcomes among persons with and with severe mental illness. Psychiatr Serv 2004;55:892-900.

30. Weiss AP, Henderson DC, Weilburg JC, Goff DC, Meigs JB, Cagliero E, Grant RW. Treatment of cardiac risk factors among patients among patients with schizophrenia and diabetes. Psychiatr Serv 2006;57:1145-1152.

31. Krein SL, Bingham CR, McCarthy JF, Mitchinson A, Payes J, Valenstein M. Diabetes treatment among VA patients with comorbid serious mental illness. Psychiatr Serv 2006;57:1016-1021.

32. Whyte S, Penny C, Phelan M, Hippisley-Cox J, Majeed A. Quality of diabetes care in patients with schizophrenia and bipolar disorder: cross-sectional study. Diabet Med 2007;24:1442-1448.

33. Goldberg RW, Kreyenbuhl J, Medoff DR, Dickerson FB, Wolheiter K, Fang LJ, Brown CH, Dixon LB. Quality of diabetes care among adults with serious mental illness. Psychiaitr Serv 2007;58:536-543.

34. National Committee for Quality Assurance. The State of Health Care Quality 2009. at: http://www.ncqa.org/Portals/O/Newsroom/SOHC/SOHC_2009.pdf (Accessed on July 2, 2010).

35. Deyo RA, Inui TS, Sullivan B. Noncompliance with arthritis drugs: magnitude, correlates, and clinical implications. J Rheumatol 1981;8:931-936.

36. Peterson GM, McLean S, Millingen KS. Determinants of patients compliance with anticonvulsant therapy. Epilepsia 1982;23:607-613.

37. Steiner JF, Koepsell TD, Fihn SD, Inui TS. A general method of compliance assessment using centralized pharmacy records. Med Care 1988;26:814-823.

38. Steiner JF, Fihn SD, Blair D, Inui TS. Appropriate reductions in compliance among well-controlled hypertensive patients. J Clin Epidemiol 1991;44:1361-1371. 